\title{
Outcome of Surgical Management of Bimalleolar Fractures - our Experience
}

\author{
Dr Voligi Shekhar, Ms(Ortho $)^{1}$,Dr Gunda Veera Reddy ${ }^{2}$, \\ ${ }^{1,2}$ Assistant Professor, Dept Of Orthopaedics, Osmania Medical College, Hyderabad, INDIA.
}

\begin{abstract}
Ankle injuries gain importance because body weight is transmitted through it and locomotion depends upon the stability of this joint. Malleolar fractures are one of the most common fractures in orthopaedic traumatology. As with all intra articular fractures, malleolar fractures necessitate accurate reduction and stable internal fixation. Previously most of the studies have not obtained good results in cases of bimalleolar fractures. The purpose of this study is to assess the functional outcome and results of surgical treatment of malleolar fractures at our institution.

Patients who sustained ankle injuries with malleolar fractures and admitted in our hospital from 2014-2016 were included in the study. The treatment of bimalleolar fractures with open reduction and stable internal fixation using AO principles was found to give a high percentage of excellent and good results. This study supports these conclusions and advocates the advantages of early mobilisation after surgery.
\end{abstract}

Manuscript

\section{Introduction}

Sir Robert Jones said "Ankle is the most injured joint of the body but the least well treated" ${ }^{1}$. Ankle injuries gain importance because body weight is transmitted through it and locomotion depends upon the stability of this joint. They are usually mixed injuries, ligamentous and bony and each injury is an end result of the sequence of ligamentous and bony failure due to deforming forces. Malleolar fracture have varied presentations which have given rise to a wide variety of classification systems, of which two are invogue Lauge - Hansens and Danis - Weber classification.Malleolar fractures are one of the most common fractures in orthopaedic traumatology. As with all intra articular fractures, malleolar fractures necessitate accurate reduction and stable internal fixation. When malleolar fractures are not reduced accurately they may lead to post traumatic painful restriction of motion or osteoarthritis or both ${ }^{2}$.Many of the fractures which are stable are reduced by conservative treatment and have given good result. The other unstable displaced and open fractures require open reduction internal fixation. The superiority of ORIF over closedtreatment have been thoroughly demonstrated in literature ${ }^{3}$. However all studies have not obtained good results in cases of bimalleolar fractures. The purpose of this study is to assess the functional outcome and results of surgical treatment of malleolar fractures at our institution.

\section{Methodology}

Patients who sustained ankle injuries with malleolar fractures and admitted in our hospital from 20142016 were included in the study. Injuries more than 2 weeks old, compound grade II and III injuries, trimalleolar injuries and infected wounds around ankle or previously operated cases were excluded.The demographic profile (i.e. age, sex) were noted. After careful history and examination, necessary radiographs of ankle were taken. In emergency department leg was elevated after correcting deformity and POP slab was applied. All the patients were evaluated medically and base line investigations were carried out. Pre operative antibiotics were given in all the cases at the time of induction of anaesthesia within 60 minutes. The patients were operated under anesthesia by open reduction and internal fixation with AO technique. Patients follow up was done in outpatient department at 2 weeks, 6 weeks and 6 months. X-rays were made to see for the union.Functional and radiological results were analyzed using the ankle scoring system of Biard and Jackson ${ }^{4}$.(TABLE 1\&2) The evaluation was based on a questionnaire and physical and radiological examination. Physical examination included the measurement of active dorsiflexion and plantar flexion of injured ankle compared with the uninjured ankle, with forepart of foot in neutral position. Radiologically the medial clear space superior joint space and talar tilt was measured. Results were analysed. 


\begin{tabular}{|c|c|}
\hline & Points \\
\hline \multicolumn{2}{|l|}{ Pain } \\
\hline A. No pain & 15 \\
\hline B. Mild pain with strenuoras activity & 12 \\
\hline C Mild pain with activities of daily living & 8 \\
\hline D. Pain with weight-bearing & 4 \\
\hline E Pain at rest & 0 \\
\hline \multicolumn{2}{|l|}{ Stability of ankle } \\
\hline A. No clinical instability & 15 \\
\hline B. Instability with sports activities & 5 \\
\hline C. Instability with sctivities of daily living & 0 \\
\hline \multicolumn{2}{|l|}{ Ability to walk } \\
\hline A. Able to walk desired distances without limp or pain & 15 \\
\hline B. Able to walk desired distances with mild limp or pain & 12 \\
\hline C. Moderately restricted in ability to walk & 8 \\
\hline D. Able to walk short distances only & 4 \\
\hline E Unable to walk & 0 \\
\hline \multicolumn{2}{|l|}{ Ability to work } \\
\hline A. Able to perform usaal occupation without restrictions & 10 \\
\hline B. Able to perform usual oceupation with restrictions in some strenuous activities & 8 \\
\hline C Able to perform usual occupation with substantial restriction & \\
\hline D. Partially disabled; selocted jobs only & 6 \\
\hline \multirow{3}{*}{\multicolumn{2}{|c|}{ E Unable to works }} \\
\hline & \\
\hline & \\
\hline A. Within $10^{\circ}$ of uninjured ankle & 10 \\
\hline B. Within $15^{\circ}$ of uninjured ankle & 7 \\
\hline C. Within $20^{\circ}$ of uninjured ankle & 4 \\
\hline D. $\angle 50 \%$ of uniniured ankle, or dorsiflexion $<5^{\circ}$ & 0 \\
\hline \multicolumn{2}{|l|}{ Radiographic result } \\
\hline $\begin{array}{l}\text { A. Anatomical with intact mortise (normal medial clear space, normal superior } \\
\text { joint space, po talar tilt) }\end{array}$ & 25 \\
\hline B. Same as $A$ with mild reactive changes at the joint margins & 15 \\
\hline $\begin{array}{l}\text { C. Measurable narrowing of the superior joint space, with saperior joint space }>2 \\
\text { mm, or talar tilt }>2 \mathrm{~mm}\end{array}$ & 10 \\
\hline $\begin{array}{l}\text { D. Moderate narrowing of the superior joint space, with superior joint space } \\
\text { between } 2 \text { and } 1 \mathrm{~mm}\end{array}$ & 5 \\
\hline E Severe narrowing of the superioc joint space, with superior joint space $<1 \mathrm{~mm}$, & \\
\hline $\begin{array}{l}\text { widening of the medial elear space, severe reactive changes } \\
\text { (sclerotic subchoodral boce and osteophyte formation) }\end{array}$ & 0 \\
\hline \multirow{2}{*}{\multicolumn{2}{|c|}{ Maximam possible seore }} \\
\hline & 100 \\
\hline
\end{tabular}

Table 1 : Biard and Jackson Ankle scoring System

\begin{tabular}{|l|l|}
\hline \multicolumn{2}{|l|}{ Interpretation Of Biard And Jackson Ankle Scores } \\
\hline Excellent & $96-100$ \\
\hline Good & $91-95$ \\
\hline Fair & $81-90$ \\
\hline Poor & $0-80$ \\
\hline
\end{tabular}

Table 2 : interpretation of Board and Jackson Ankle Scoring system.

\section{Results}

In our study, 80 cases of bimalleolar fractures of ankle were treated by surgical methods. The mean age was 39.6 years (Table 3).Right side was involved in 25 (62.5\%) cases and left ankle in 15 (37.5\%). Road traffic accident was the most common mode of injury and majority of the patients were males, with M: F ratio of 3:2.3 


\begin{tabular}{|l|l|}
\hline $18-30$ & 24 \\
\hline $31-40$ & 34 \\
\hline $41-50$ & 12 \\
\hline $51-60$ & 10 \\
\hline
\end{tabular}

Table 3 : Age Incidence

Medial malleolar fractures were fixed with malleolar screws and the lateral malleolar fractures were fixed with one third tubular plate. In two cases $(5 \%)$ syndesmotic injury was noted and in these two cases it was fixed with a fully threaded screw. Weight bearing was deferred till screw removal which was done at 6-8 weeks.

\begin{tabular}{|l|l|}
\hline SE & 30 \\
\hline SA & 10 \\
\hline PA & 16 \\
\hline PE & 24 \\
\hline
\end{tabular}

Table 4 : Classification of injuries in the study group. (SE, supination-external rotation; SA, supinationadduction; PA, pronation-abduction; PE, pronation external rotation)

In our study, the average time taken for union was 10.4 weeks. Most of the cases $(80 \%)$ showed union between 8-12 weeks.In our study, 4 patients had superficial infection, 1 patient deep infection, 2 patients delayed union medial malleolus. The infections (superficial and deep) were managed with debridement and antibiotics. Delayed union of medial malleolus was treated with continued immobilization, which eventually united without surgical intervention. Unilateral swelling of the operated side was the commonest complaint in the post-op follow up even at 6 months in 46 patients. In this study, excellent results were achieved in 46 cases (57.5\%), good in 20 cases $(25 \%)$, fair in 10 cases $(12.5 \%)$ and poor results in 4 cases $(5 \%)$. The patients with poor results had mild pain during their activities of daily living.

\section{Discussion}

Increased knowledge about the normal and post traumatic anatomy and function of the ankle joint has lead to demands for exact reduction and rigid fixation of the ankle fractures. Prompt operative treatment of displaced ankle fractures decreases morbidity and improves functional outcome. ${ }^{5,6}$ The treatment of malleolar fractures with accurate open reduction and stable internal fixation using AO method and principles was found to give a high percentage of excellent and good results. 2 This study supports these conclusions.

Although the scoring of Baird and Jackson has proven to be strict allowing only very small fluctuation from normal about $65 \%$ patients in this series achieved excellent results by that scoring system and $25 \%$ patients achieved good results and also had anatomical reduction of the lateral malleolus as well as anatomical reduction of talus radiologically.

In a study conducted by Beris et $\mathrm{al}^{2}$ of 144 patients with ankle fracture there were good to excellent results in $74.3 \%$ patients, fair results in $14.6 \%$ and poor result in $11.1 \%$. All these were comparable to our study.

Observation in this study support the contention of Yablon et al ${ }^{7}$ that lateral malleolus is the key to the anatomical reduction of bimalleolar fractures, because the displacement of the talus faithfully followed that of the lateral malleolus. Poor reduction of distal part of fibula would result in persistent lateral displacement or residual shortening. This does not necessarily lessen the importance of the medial malleolus in contributing to the congruity of medial aspect of ankle, but it does serve to emphasize that the lateral malleolus should no longer be ignored in the treatment of ankle injuries. The patient who had poor result did not have anatomical reduction of lateral malleolus.

The extent of skeletal involvement had a significant prognostic value in the outcome where unimalleolar and bimalleolar fracture were associated with better result compared with trimalleolar fractures. The presence of a posterior bony fragment greater than $25 \%$ of the joint surface has been shown previously to 
affect the outcome and increase the risk of osteoarthritis. However, we feel our study has limitation in not comparing the bimalleolar fracture fixation with trimalleolar injuries which could have given more information.

Although early mobilization was advocated by $\mathrm{AO}$, immobilization also has been supported. Others have found no significant difference in the results produced after early motion or immediate plaster splintage ${ }^{2}$. In this series patients were allowed to do ankle ROM exercises with non weight bearing walking immediately after surgery and partial weight bearing at 6 weeks. The range of motion was reduced initially but rapidly improved as swelling subsided. A number of different treatment regimens have been suggested. Burwell and Charnley ${ }^{6,8}$. Postoperative joint mobility exercises in bed until motion was restored followed by full weight bearing in a cast. Makwana et al ${ }^{9}$ either used no cast or applied one for a few days postoperatively and then allowed full joint mobilization out of the cast. They advocated the use of crutches to maintain a non weight bearing status. Bostman 10 used a post operative cast but only for an average of 3.8 weeks followed by nonweight bearing mobilization until fracture union. Probably early rehabilitation is the key to success in achieving excellent outcome.

\section{Conclusion}

The treatment of bimalleolar fractures with open reduction and stable internal fixation using AO principles was found to give a high percentage of excellent and good results. This study supports these conclusions and advocates the advantages of early mobilisation after surgery.

\section{References}

[1]. Shelton Marvin L. Complication of fractures and dislocation of the ankle. In: Complications in orthopaedic surgery, Chapter 23,3 rd edn., Vol.I, edt. EPPS, Charles H, Philadelphia : J.B. Lippincott Company, 1994; 595-648pp.

[2]. Beris AE, Kabbani KT, Xenakis TA, Mitsionis G, Soucacos PK, Soucacos PN. Surgical treatment of malleolar fractures - a review of 144 patients. Clin Orthop Related Research, 1997 Aug; 341: 90-98.

[3]. Weber MJ. Ankle fractures and dislocations. In : Operative orthopaedics, Chapter-50, 2 edn., Vol.3, Ed. Chapman MW, Madison M. Philadelphia : J.B. Lippincott Company, 1993; 731-748pp.

[4]. Baird RA and Jackson ST. Fracture of the distal part of fibula with associated disruption of the deltoid ligament. J Bone Joint Surg, 1987; 69A: 1346-52.

[5]. Muller ME, Allgower M, Scheider R, Willenegger H. Manual of internal fixation : techniques recommended by the AO-group, $3^{\text {rd }}$ edn, New York: Springer- Verlag, 1991.

[6]. Burwell $\mathrm{HN}$ and Charnley AD. The treatment of displaced fractures at the ankle by rigid internal fixation and early joint movement. J Bone Joint Surg, 1965; 47B: 634-660.

[7]. Yablon IG, Heller FG, Shouse L. The key role of the lateral malleolus in displaced fractures of the ankle. J Bone Joint Surg, 1977; 57A: $169-173$

[8]. DeSouza LJ, Gustilo RB, Meyer TJ. Results of operative treatment of displaced external rotation - abduction fractures of the ankle. J Bone Joint Surg, 1985; 67A: 1066-1074.

[9]. Makwana NK, Bhowal B, Harper WM, Hui AW. Conservative versus operative treatment for displaced ankle fractures in patients over 55 years of age. JBJS, 2001 May; 83(B): 525-529.

[10]. Bostman O, Hirvensalo E, Vainiopaa S, et al. Ankle fractures treated using biodegradable internal fixation. Clin Orthop, 1989; 238: 195-203. 